\title{
REPRESENTACIONES SOBRE LO RURAL Y LAS TIC. REFLEXIONES A PARTIR DE UN ESTUDIO DE CASO EN LA PROVINCIA DE SAN LUIS, ARGENTINA ${ }^{1}$
}

\author{
MARÍA ELISA FORNASARI \\ Universidad Nacional de San Luis, \\ Villa Mercedes, San Luis, Argentina \\ Becaria CONICET \\ E-mail: eli_fornasari@hotmail.com.
}

1 Este trabajo surge del curso de Posgrado "Medios y Tics: consumos, identidades y representaciones", dictado en diciembre de 2013 por la Dra. Ada Machado Silveira (UFSM) en la Universidad Nacional de San Luis, Argentina y está basado en una tesis de posgrado perteneciente a quien escribe. 
REPRESENTACIONES SOBRE LO RURAL Y LAS TIC. REFLEXIONES A PARTIR DE UN ESTUDIO DE CASO EN LA PROVINCIA DE SAN LUIS, ARGENTINA

Resumen: El artículo presenta, a partir de un estudio de caso en una localidad rural de la provincia de San Luis, Argentina, una reflexión sobre las representaciones que existen en torno a la relación entre TIC y los ámbitos rurales, abordadas éstas en dos planos: en relación a las formaciones culturales que aún perduran al pensar el campo como un espacio de atraso, y por otra parte, las representaciones que surgen a partir de la incorporación de TIC en la ruralidad, cuya presencia coexiste con las que siempre existieron, bajo el supuesto de posibles tensiones.

Palabras clave: representaciones; TIC; ruralidad

REPRESENTAÇÕES SOBRE O RURAL E TIC. REFLEXÕES DE UM ESTUDO DE CASO NA PROVÍNCIA DE SAN LUIS, ARGENTINA

Resumo: $O$ artigo apresenta, a partir de um estudo de caso numa localidade rural da província de San Luis, Argentina, uma reflexão sobre as representações que existem em torno da relação entre TIC e os âmbitos rurais, abordadas estas em dois planos: em relação às formações culturais que persistem ao pensar o campo como um espaço de atraso, e por outra parte, as representações que surgem a partir da incorporação de TIC na ruralidade, cuja presença coexiste com as que sempre existiram, baixo o suposto de possíveis tensões.

Palavras chave: representações; TIC; ruralidade.

REPRESENTATIONS ABOUT THE RURAL AND ICT. REFLECTIONS FROM A CASE STUDY IN THE PROVINCE OF SAN LUIS, ARGENTINA

Abstracts: The article presents, from a study of case in a rural place of the province of San Luis, Argentina, a reflection on the representations that exist around the relation between TIC and the rural fields, tackled these in two levels: in relation to the cultural trainings that persist when thinking the field as an area of backwardness, and on the other hand, the representations that arise from the incorporation of TIC in the rural, whose presence coexists with that ever existed, under the supposition of possible tensions.

Keywords: representations; TIC; rural place. 


\section{INTRODUCCION}

En el presente artículo, se entiende que el proceso de emergencia de herramientas tecnológicas en diversos ámbitos de la vida cotidiana se ha profundizado en los últimos años, de la mano de políticas públicas e intereses privados que repercuten en la constitución de relaciones al interior de lo social (CASTELLS, 1997; MORLEY, 2007).

La fuerza de este fenómeno ha trascendido las dimensiones témporo espaciales (GIDDENS,1997) y ha llevado que las TIC se incorporen en diferentes escenarios y con diversa intensidad también en los ámbitos rurales, donde han incidido en las maneras en que se experimentan las culturas locales, los vínculos, las pautas de interacción y socialización. La comunicación, integrada a la construcción de identidades y subjetividades sociales y a las prácticas cotidianas situadas (FUENTES NAVARRO, 2011), si bien se comprende desde la perspectiva sociocultural, ha adquirido nuevas formas de manifestación a partir de la emergencia de la virtualidad como un fenómeno todavía desconocido en sus límites, que se inserta en la realidad conocida y entabla nuevas relaciones con la misma, la expande, la desata de las dimensiones de tiempo y espacio (MACHADO SILVEIRA, 2001).

A partir de lo desarrollado en el seminario "Medios y TIC", el presente trabajo intenta hacer una aproximación a las representaciones que se ponen en juego a la hora de la apropiación de estas tecnologías en localidades rurales.

Hablaremos de representaciones en dos planos: por una parte las abordaremos en relación a las formaciones culturales que aún perduran al pensar en el campo como un espacio de atraso, es decir, imágenes que viven en lo social y que los medios de comunicación han vehiculizado a lo largo del tiempo. Por otra parte, nos centraremos en aquellas representaciones que surgen a partir de la incorporación de TIC en la ruralidad, cuya presencia coexiste con las que siempre existieron, bajo el supuesto de posibles tensiones. Este segundo apartado lo abordaremos en términos de aproximación ya que responde a una pregunta surgida a partir del seminario antes citado y no ha sido exhaustivamente indagado previo trabajo en el campo.

Partiendo del supuesto que las herramientas tecnológicas y las posibilidades que vehiculizan han crecido y se han diseminado, en primera instancia ante la necesidad del ser humano de dominar su entorno, cierto es que desde el siglo pasado otras fuerzas como las del mercado y la presencia de industrias culturales han tomado la delantera en cuanto a utilizar los medios de co- 
municación para construir representaciones de la realidad. Ello nos lleva a re-pensar desde lo comunicacional los procesos de incorporación de TIC en los ámbitos rurales y especialmente referirnos a las representaciones construidas como imágenes que conforman lo real al ser "hechos de palabra o discurso y de práctica social” (LEFEBVRE, 1983 citado por MACHADO SILVEIRA, 2001).

Pretendemos que sean estas mismas ideas las que nos ayuden a reflexionar sobre la relación entre TIC-representaciones construidas sobre/en lo rural y apropiación de TIC en la ruralidad, en un intento por transitar el camino de la desmitificación de los imaginarios que están naturalizados sobre esta relación. Nos centraremos especialmente en los y las jóvenes por ser quienes en mayor medida han experimentado y experimentan relación con la tecnología, además de constituirse el núcleo donde se centra la investigación del citado trabajo de posgrado.

La experiencia que sirve de base para esta reflexión forma parte de una tesis de maestría donde se ha realizado una aproximación a las prácticas y sociabilidades puestas en juego a partir de la incorporación de TIC en la localidad rural de Juan Jorba, Departamento General Pedernera de la provincia de San Luis, Argentina. El estudio ha intentado trascender las derivas meramente descriptivas de las maneras en que se establecen los usos y se presentan las habilidades de las juventudes y se ha interrogado por las tensiones y conflictos inscriptas en los procesos de negociación de los sentidos que la tecnología adquiere en las dinámicas cotidianas.

Las preguntas que aquí surgen son por dos fenómenos diversos que se relacionan con la idea de representación. Por un lado, interrogarnos por lo rural representado como el espacio de lo antiguo, atrasado, tradicional; características que han atravesado y atraviesan el imaginario que se teje sobre estos espacios y el proceso de incorporación de TIC dentro de este escenario. Por otro lado, la pregunta es por las representaciones ligadas a la presencia de las Tecnologías de la Información y Comunicación en contextos rurales y las maneras en que efectivamente esta presencia se incorpora en Juan Jorba, el caso particular de estudio. ¿Cómo operan estas imágenes representacionales en estos dos procesos? ¿Qué lugar cabe a los sujetos en estos fenómenos? ¿Qué atravesamientos políticos, culturales e históricos se tejen?

Lejos estamos de poder dar respuestas a estos interrogantes, no obstan-

1 Maestría en Sociedad e Instituciones. Facultad de Ciencias Económicas, Jurídicas y Sociales, Universidad Nacional de San Luis, Argentina 
te lo cual abordaremos reflexivamente estas problematizaciones. Para ello nos guiaremos especialmente por los aportes realizados por Ada Machado Silveira a partir de su trabajo "Asombros identitarios" y "La virtualización de las representaciones identitarias" (2001), así como el aporte de diversos autores que han avanzando en el estudio de la comunicación rural.

\section{PRIMERO, UNA APROXIMACIÓN AL CONTEXTO DE ESTUDIO}

Juan Jorba está ubicada en la zona centro-este de la provincia de San Luis, Argentina, en el departamento General Pedernera, se encuentra a una distancia de $117 \mathrm{~km}$. de la capital provincial, a $20 \mathrm{~km}$. de la segunda ciudad más importante de la provincia (Villa Mercedes) y cuenta con 150 habitantes. En la imagen 1 se muestra la ubicación de la provincia en el contexto nacional y en la imagen 2 se detalla la ubicación de la localidad de Juan Jorba.

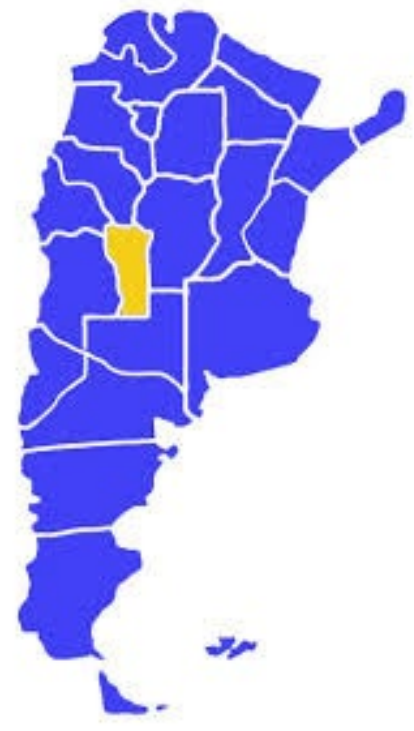

Imagem 1

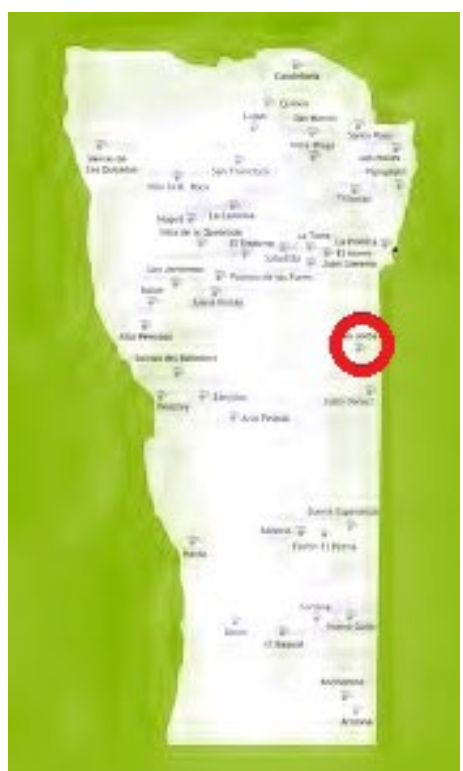

Imagem 2

El perfil productivo de Jorba es claramente agrícola -ganadero. La actividad agrícola se encuentra orientada a la producción de maíz, sorgo y girasol, incorporándose un los últimos años la soja como oleaginosa alternativa.

La ganadería que se desarrolla es fundamentalmente de invernada con algunos establecimientos dedicados a la cría vacuna y porcina. De ser una zona mayoritariamente ganadera, en los últimos años ( $y$ fundamentalmente

2 El trabajo "Asombros Identitarios" de Machado da Silveira, Ada C, es un estudio inédito, por lo cual no se han consignado los datos completos (sin fecha). 
tras el boom sojero), la agricultura fue ganando espacio hasta constituirse en una actividad que ocupa cerca del $70 \%$ de la producción actual. También la producción de alfalfa adquiere una gran importancia al tener un área de aproximadamente 10.000 has destinadas a la actividad.

Respecto a la actividad industrial, en la localidad hay dos importantes empresas, una dedicada al reciclado y planchado del metal, donde se ocupan 10 empleados fijos y otra dedicada a la producción de agroalimentos para bovinos y porcinos donde se ocupan 15 empleados, además del sector administrativo.

En Jorba, como en otras poblaciones rurales de la provincia, el contacto de los habitantes con las herramientas digitales se profundizó a partir de la política provincial de "Inclusión Digital", destinada a la población de zonas urbanas y rurales y cuya principal bandera ha sido la entrega de computadoras a los niños y jóvenes y la extensión de la cobertura de Internet a toda la superficie provincial, entre otras variadas iniciativas y proyectos que la acompañan que no es posible especificar aquí porque excedería las posibilidades del presente artículo.

\section{LO URBANO, LO RURAL, LO MARGINAL}

Las representaciones, entendidas como lo que queda de aquello que ya no se encuentra entre nosotros, son "formaciones culturales sintéticas, abstracciones complejas (...) que nos concretan algo, nos obsequia con una información dirigida hacia nuestra sensibilidad" (MACHADO SILVEIRA, p. 45). Las representaciones se solidifican en nuestra vida cotidiana allí donde vienen a llenar una ausencia, ocupando el intervalo entre lo vivido y lo concebido, lo ausente y presente (LEFEBVRE, 1983). Haciendo una referencia histórica de cómo lo visual ha adquirido protagonismo sobre otras formas en su vínculo con la representación, debemos nombrar al sistema representacional euroccidental que se vería facilitado por las cualidades de las tecnologías (como la televisión) que han conservado "la alineación entre sujeto, objeto e imagen, en el tiempo y en el espacio" (... ) y junto con esto, su cualidad de adherencia a lo real que le permitió una sobre representación ( COUCHOT, 1993 citado por MACHADO SILVEIRA) y con ello la dificultad de diferenciar lo que es real de lo que es mediáticamente representado (Machado Silveira).

Dichos elementos arrojan algo de luz sobre los orígenes del pensamiento sobre lo rural (momento en que se vuelve tematizable y posible de problematización) y sobre porqué la imagen de atraso ha sido la que más fuer- 
temente prevaleció en torno a él. Una de las posibilidades hay que buscarla en la constitución/lógica/intereses de los medios de comunicación y los nuevos medios y su relación con las representaciones, así como también en las disciplinas que originalmente se preocuparon por estudiar la ruralidad.

En relación a esto último, la sociología (DA SILVA, 1988 citado por CIMADEVILLA, 1997)3) ha sido uno de los campos fundantes de los estudios sobre lo rural, habida cuenta que es la disciplina que históricamente se ha preocupado por estudiar la vida en estas áreas y las diferencias con lo urbano (TÖNNIES,1947) especialmente en momentos de crecimiento de las ciudades producto de la modernidad y los procesos ligados a ella. Es a partir de los estudios sociológicos, que se origina en tiempos de la modernidad la preocupación por conocer la vida en el campo y al diferenciarla con la ciudad, se crea el imaginario contrapuesto vinculado al atraso, lo rudimentario, en una suerte de folclorización del mundo agrario. La imagen de lo rural fundada sobre esta diferencia se constituyó en una representación en tanto una categoría estable en el espacio y el tiempo. Más aun, lo rural concebido como lo alejado, se hace real a partir de llenar la distancia entre lo ausente y lo presente (LEFEBVRE, 1982), se realiza a partir de su imagen representada.

En este orden de cosas bien puede considerarse que gran parte de los sistemas de interpretación que han existido y aún hoy persisten hunden sus raíces en la matriz occidental y bajo un modelo específico de comprensión de lo real (MORLEY, 2007). Si se comprende que los nuevos medios vehiculizan y refuerzan representaciones, es importante reconocer que los media y las tecnologías no son aparatos, discursos e instituciones aislados o faltos de lógica, y de allí la fuerza que toman ciertas imágenes sobre otras.

Ahora bien, y avanzando sobre la segunda cuestión que interesa problematizar ¿cómo se actualiza/relaciona esta representación con la presencia de TIC en estos espacios? ¿De qué manera se da la apropiación de estas herramientas en la ruralidad?

Es importante hacer referencia a la tipología de medios que construye Harry Pross (1987) quien los diferencia en primarios, secundarios y terciarios. Los medios primarios, se asientan en la capacidad de comunicación del mismo sujeto a partir de la proxémica, los gestos y ceremoniales. Éstos se relacionan a los mundos rurales en tanto se los represente tradicionales y li-

3 Extraído del Segundo Seminario de Comunicación Rural organizado por INTERCOM en Brasil (1988). 
gados a una forma de comunicación donde prosperan las formas directas de vincularse. El dominio de la oralidad, como el espacio privilegiado de comunicación entre actores del campo y entre ellos y los habitantes de la ciudad (CARNIGLIA, 2011) no es una realidad dada, sino un "emergente de algunas condiciones culturales de los ámbitos rurales cuanto una consecuencia de los modos en que se construyó socialmente la ruralidad" (CARNIGLIA, 2011, p. 421) Pensado de esta manera se desnaturaliza una imagen creada que vincula directamente la preeminencia de medios llamados primarios a los contextos agrarios.

A partir de la introducción de las TIC en lo rural, emergen los medios terciarios caracterizados por la presencia de un soporte tanto en el momento de la emisión como en el proceso de recepción del mensaje. Con ello aparecen fenómenos nuevos en la experiencia del sujeto en tanto cambian las maneras de vincularse, ahora atravesados por la virtualidad que transforma las relaciones y la realidad, modificándolas. La realidad se transforma en tanto la presencia de TIC no se reduce sólo a la incorporación de una herramienta sino que produce una interrelación entre lo local y lo global, una separación espaciotemporal y con ello la proliferación de no-lugares (MACHADO SILVEIRA), fenómenos sumamente significativos porque modifican dimensiones constitutivas del ser humano y su experiencia material y simbólica.

De la interrelación global/local y la proliferación de no-lugares, posibilitada por los procesos comunicativos y la presencia de las tecnologías, surge una tensión contradictoria, asentada en la valoración de lo cercano culturalmente construida en la ruralidad y la contraposición con los procesos que incorporan la idea de fugacidad, fragmentación, desterritorialización, propia de los fenómenos globales actualmente presentes a partir de las TIC.

En Juan Jorba, a modo de ejemplo, el trabajo de campo basado en la observación y entrevistas en profundidad, dio cuenta de una manera especial de apropiación de las TIC por parte de los habitantes. Estos le otorgan sentido según sus trayectorias de vida y las llenan de significado siempre atravesados por sus rutinas cotidianas, donde las prácticas de estudio, las tareas en el núcleo familiar, las actividades diarias, los intercambios cara a cara con sus pares, siguen siendo predominantes y a partir de allí se relativiza la importancia de las tecnologías a la vez que se las utiliza continuamente. Estos elementos hacen referencia a procesos de apropiación que son específicos a este espacio y habitantes y que se construyen en el proceso de negociación y resignificación de las herramientas tecnológicas según los 
intereses, las habilidades prácticas y cognoscitivas respecto a las herramientas, etc. No obstante ello, un punto donde es interesante centrarse es allí donde la observación se vuelve más compleja, es decir, en el espacio de la virtualidad. Reconociendo que las fronteras entre lo urbano y rural son cada vez más difusas, lo que se construye en el espacio virtual debilita aún más esas fronteras urbano/rural y evidencia maneras de relacionarse a través de la red que se vuelven comunes a los diversos ámbitos. Entrevistados en relación a ello, los y las jóvenes de Jorba reconocen hacer un uso profuso de las redes sociales (facebook) y, si bien los contactos son en su mayoría con conocidos cercanos, las maneras en que se construyen subjetividades, los usos que se realizan y las formas en que se vinculan con otros sujetos, son similares a las que pueden establecerse en otros contextos. Entonces, se supone que se establece en esta práctica una suerte de homogeneización de la relación con las TIC que incorpora una lógica de la virtualidad que trasciende los espacios y los territorios donde se producen. Homogeneización no en el sentido que el uso y la apropiación se torna pasivo, acrítico, exento de las riquezas y diversidades propias de las experiencias particulares que se ponen en juego, sino en el hecho que los sujetos que interactúan en la red pertenecen a un cuerpo desterritorializado, que construye múltiples identidades $y$, en tanto se encuentra zambullido en el espacio virtual, no se diferencia en términos de su procedencia (urbano, rural, país de origen, etc), ni de las actividades que realiza fuera de la virtualidad (estudio, actividades culturales, actividades relacionadas a la producción rural, etc). Aquí es posible reconocer lo que Machado Silveira considera como una de las características de la representación cultural actual, determinada a su vez por la presencia de las tecnologías, a saber: "ser sujeto, o tener conciencia de su subjetividad, no es lo mismo que ser individuo, puesto que este puede ser muchos sujetos a la vez, aunque pueda tener un único cuerpo" (MACHADO SILVEIRA, p.126).

En el trabajo de tesis realizado que he citado anteriormente, así como en este, tanto las juventudes como las tecnologías se suponen construidas socialmente y como parte de un contexto particular. (CHAVES, FAUR, 2000 MATTELART, SCHMUCLER, 1983; BARBERO, 1987). Bajo esta concepción teórico-epistemológica, comprendemos que las juventudes que habitan la ruralidad se conciben bajo una naturaleza diferencial respecto a aquellas que habitan otros contextos. Si bien no se esencializa su condición ni se las piensa caracterizadas de manera estanca, se comprende que las condiciones estructurales, las instituciones que las atraviesan, facilitan u obstaculi- 
zan posibilidades y propician la constitución de juventudes diversas.

No obstante ello, la reflexión que propicia el problematizar la apropiación de TIC en espacios rurales teniendo en cuenta las representaciones en la virtualidad, daría cuenta de una realidad diferente, y de representaciones que son propias del espacio virtual. En este sentido, si bien no se aíslan de los condicionantes que resultan de las historias de vida particulares, sí generan identidades que son propias de este ámbito creado a partir de las tecnologías. Sin ánimo de realizar aseveraciones, sino en un intento de seguir pensando, puede considerarse que es en la virtualidad donde se conforman representaciones específicas y donde las diferencias se hacen aún más difusas.

¿Cómo relacionar las representaciones que existen sobre lo rural y aquellas que se generan y emergen de la virtualidad? Tal como consideramos al inicio, pertenecen a dos planos diferentes de la experiencia pero fuertemente interrelacionados. Una a la par de la otra se van modificando ya que conviven y se condicionan. Comprender por qué la representación sobre el campo ha estado vinculado a la folclorización ayuda a desnaturalizar lo dado y a entender que la incorporación de TIC, medios terciarios, la existencia de vínculos que trascienden lo personal y modifican la experiencia de relación, transforman también dichas imágenes que se presentaban como estables (no sólo las TIC sino las transformaciones socioeconómicas). A la vez, es significativo preguntarse qué ausencia están llenando actualmente las TIC, especialmente en los espacios rurales de nuestro interés, si a partir de ello comprendemos el lugar de las representaciones. Damos por sentado el hecho que la tecnología no se vincula al desarrollo sin más, que su presencia conlleva lo político y que es necesario alejarse de las miradas extremas reticencia/optimismo en cuanto a su presencia. Desde este lugar, entonces, tal como señala Machado Silveira:

La investigación en comunicación tiene el compromiso de reflexionar sobre los usos sociales que son trabajados mediante las nuevas tecnologías, el desarrollo de sus aplicaciones y técnicas, predecir sus posibles efectos, involucrarse en el diseño e implementación de nuevos sistemas de comunicación antes de su institucionalización (p.5). 


\section{CONCLUSIÓN}

El trabajo ha constituido una "plataforma de pensamiento", un espacio para reflexionar sobre fenómenos relacionados a las representaciones que existen en dos planos: las referidas a los mundos rurales en torno a los cuales subsisten imágenes naturalizadas y propias de un acervo; y las representaciones emergentes a partir de la incorporación de TIC a una localidad rural particular, Juan Jorba. En este último caso, haciendo referencia a las imágenes que moviliza dicha presencia (sobre todo en las juventudes porque es desde donde parte nuestro interés) y las que se crean en la práctica misma de apropiación.

Si bien este escrito ha constituido una aproximación, parte de interrogantes en torno a los elementos políticos, culturales e históricos que subyacen a las miradas que persisten sobre lo rural y especialmente a los procesos de incorporación de tecnología y nuevos medios ¿Cómo se tensionan y relacionan ambos planos de representación? ¿Qué espacio vienen a llenar? ¿Qué ausencias, dificultades, estados de cosas se manifiestan en la virtualización? ¿Qué elementos son importantes desnaturalizar y develar en torno a los mundos rurales y su relación con las TIC?

Los interrogantes, como insumo y punto de partida para la tarea de investigación e indagación, son los elementos que emergen para multiplicarse, constituirse en caminos posibles, dar rienda suelta a la crítica y el análisis, en fin, están allí esperando el momento de salir a la luz.

\section{REFERENCIAS}

BARBERO, Jesús Martín. De los medios a las mediaciones. Comunicación, cultura y hegemonía. Ediciones G. Gili. México, 1987.

CARNIGLIA, Edgardo. Las TIC en el campo moderno. Los espacios críticos de la comunicación rural. Intercom 2011. IV Coloquio Binacional Brasil-Argentina, 2011.

CASTELLS, Manuel. La era de la información. Economía, cultura y sociedad. La sociedad red. Alianza, 1997.

CHAVES, M; FAUR, E; RODRIGUEZ, M. Investigaciones sobre juventudes en Argentina: estado del arte en ciencias sociales. Proyecto Estudio Nacional sobre Juventud en la Argentina. Universidad Nacional de La Plata- La Plata, 2006.

CIMADEVILLA, Gustavo; CARNIGLIA, Edgardo; CANTÚ, Ariadna. La bocina que parla. Antecedentes y perspectivas de los estudios en Comunicación Rural. Universidad Nacional de Río Cuarto- INTA, 1997. 
FUENTES NAVARRO, Raúl (2011) Pensamiento comunicacional latinoamericano y convergencia digital. Retos epistemológicos y académicos. Del Valle Moreno y Sierra (eds.) Cultura latina y revolución digital. Matrices para pensar el espacio iberoamercano de comunicación. Barcelona: Gedisa (Multimedios. Serie Cultural Latina), 2011.

GIDDENS, Anthony. Modernidad e identidad del yo. El yo y la sociedad en la época contemporánea. Barcelona: Península, 1997.

HARRY PROSS. Introducción a la Ciencia de la Comunicación. Barcelona, 1987.

LEFEBVRE, Henry. La presencia y la ausencia. Contribución a la teoría de las representaciones, México, Fondo de Cultura Económica, 1982.

MACHADO SILVEIRA, Ada C. La virtualización de las representaciones identitarias. Revista Educacao e realidade. Jun-Jul pp. 115-123, 2001.

. Asombros identitarios. Trabajo inédito. ${ }^{4}$

MATTELART, A. y SCHMUCLER, Héctor. América Latina en la encrucijada telemática, México, 1983.

MORLEY, David. Medios, modernidad y tecnología. Hacia una teoría interdisciplinaria de la cultura. Gedisa. Buenos Aires, 2007.

\section{María Elisa Fornasari}

Licenciada en Comunicación Social, Universidad Nacional de Córdoba, Argentina. Doctoranda en Doctorado en Comunicación Social, Universidad Nacional de Córdoba.

Investigadora en Facultad de Ciencias Económicas, Jurídicas y Sociales, Universidad Nacional de San Luis, Argentina. Becaria CONICET.

4 El trabajo "Asombros Identitarios" de Machado da Silveira, Ada C, es un estudio inédito, por lo cual no se han consignado los datos completos (fecha). 